\title{
Implementation and Evaluation of a Clinical Pathway for Pancreaticoduodenectomy Procedures: a Prospective Cohort Study
}

\author{
Marion van der Kolk ${ }^{1,2}$ (D) - Mark van den Boogaard ${ }^{2}$. Femke Becking-Verhaar ${ }^{1}$. \\ Hettie Custers $^{3} \cdot$ Hans van der Hoeven ${ }^{2} \cdot$ Peter Pickkers $^{2} \cdot$ Kees van Laarhoven ${ }^{1}$
}

Received: 23 March 2017 / Accepted: 16 May 2017 / Published online: 6 June 2017

(C) 2017 The Author(s). This article is an open access publication

\begin{abstract}
Introduction Medical and nursing protocols in perioperative care for pancreaticoduodenectomy are mainly mono-disciplinary, limiting their integration and transparency in a continuous health care system. The aims of this study were to evaluate adherence to a multidisciplinary clinical pathway for all pancreaticoduodenectomy patients during their entire hospital stay and to determine if the use of this clinical pathway is associated with beneficial effects on clinical end points.

Materials and Methods A prospective cohort study was conducted in 95 pancreaticoduodenectomy patients treated according to a clinical pathway, including a variance report, compared to a historical control group $(n=52)$ with a traditional treatment regime. Results Process evaluation of the clinical pathway group revealed that protocol adherence throughout all units was above $80 \%$. Major complications according to Clavien-Dindo classification grade $\geq 3$ decreased from 27 to $13 \% ; p=0.02$. Hospital length of stay was significantly shorter in the clinical pathway group, median 10 days [IQR 8-15], compared with the control group, median 13 days [IQR $10-18] ; p=0.02$.

Conclusion The use of a clinical pathway in pancreaticoduodenectomy patients was associated with high protocol adherence, improved outcome and shorter hospital length of stay. Variance report analysis and protocol adherence with a Prepare-ActReflect Cycle are essential in surveillance of outcome.
\end{abstract}

Keywords Pancreaticoduodenectomy · Clinical pathway · Protocol adherence $\cdot$ Perioperative care

\section{Introduction}

Pancreaticoduodenectomy for pancreas tumours and periampullary tumours is considered high-risk surgery and

Marion van der Kolk

Marion.vanderKolk@radboudumc.nl

1 Department of Surgery, Radboud University Medical Center, P.O. Box 9101, 6500HB Nijmegen, The Netherlands

2 Department of Intensive Care Medicine, Radboud University Medical Center, Nijmegen, The Netherlands

3 Department of Anesthesiology, Radboud University Medical Center, Nijmegen, The Netherlands is associated with high morbidity (30-70\%) and a mortality of $1-5 \%$ in specialized centres. ${ }^{1,2}$ Centralization of pancreas surgery and advances in surgical techniques resulted in more patients being operated for advanced-staged tumours. ${ }^{3,4}$ Patients with more comorbidity receiving pre-operative chemotherapy and/or vascular reconstructions in advanced disease, need more complex perioperative care. Currently this is facilitated by multiple guidelines and medical and nursing protocols. This complexity demands an overall multidisciplinary approach and clear communication.

Different departments are involved in the treatment during the patients' journey through the surgical ward, operation theatre, post-anaesthesia care unit (PACU) and intensive care unit (ICU). However, large differences in the actual use of these protocols are present between the different units and medical and nursing staff members. ${ }^{5,}{ }^{6}$ Moreover, while multidisciplinary teamwork for these patients is essential, the development and implementation of a clinical pathway (CP) involve many aspects of the total patient care and should therefore be multidisciplinary by doctors and nurses as well. 
A CP may facilitate the care for this group of high-risk surgery patients by unifying different protocols into one multidisciplinary protocol for all units during the hospital stay of the patients. This may result in an increased protocol adherence, less morbidity and improved outcome. Key elements of a CP are guidelines, evidence-based clinical protocols and best practice rules, together with a coordinated sequence of activities of the multidisciplinary team. ${ }^{7}$ Registration, monitoring and evaluation of adherences, variances and outcomes are part of a CP and can be part of a process-driven pathway. ${ }^{8}$ A multidisciplinary $\mathrm{CP}$ has therefore many evaluation moments and scheduled actions. To keep the patient on the 'pathway', the CP mandates a registered response of the nurse or doctor if results are outside the range of the prescribed boundaries.

Many CPs have been developed for high volume with lowrisk and with average-risk health care procedures in order to reduce complications. $^{9-12}$ The post-operative phase of the patient spent in the ICU or PACU, however, is a seldom part of a CP. ${ }^{13}$ A CP including the PACU/ICU stay mandates an hourto-hour care plan during the post-operative stay in the ICU/ PACU. ${ }^{14}$ Many standardized care plans related to a pancreaticoduodenectomy have been published, focussing on the use of an enhanced recovery program after surgery (ERAS) with elements like early mobilization, early enteral feeding, pain treatment and reduction of iv fluid administrations to shorten the length of hospital stay. ${ }^{15-19}$ In these care plans, a reduction of hospital length of stay (LOS), morbidity or mortality was not always observed. Crucially, the ICU period of these patients was not integrated in these protocols.

The aim of this study was first to determine the feasibility to develop and implement a multidisciplinary $\mathrm{CP}$ including a variance report for all pancreaticoduodenectomy patients during their entire hospital stay and second to determine if the use of this CP is associated with an improvement of patient's morbidity and outcome.

\section{Methods}

\section{Setting and Patients}

The Radboud University Medical Center in Nijmegen is a 1000-bed university hospital, including a 32-bed closed-format ICU, a 5-bed PACU and a 30-bed gastrointestinal (GI) oncology surgical ward. An anaesthesiologist with a resident are supervising the PACU. The ICU is supervised by the intensivists, with intensivists-in-training and residents. They all work in close relation with the surgical team. On the surgical ward, nurses, physician assistants and young residents are caring for patients undergoing a pancreaticoduodenectomy, under daily supervision of the senior GI-oncology medical staff. Since the centralization in 2012 of pancreas surgery in the Netherlands, approximately 80 pancreas operations (60 malignant cases) are operated annually in the Radboudumc. As a result, the logistics and perioperative care of our pancreatic surgical program needed reflection and rescheduling.

\section{Development of the CP}

The development of the multidisciplinary CP for pancreaticoduodenectomy was a multistep procedure with the use of lessons learned from the development and implementation of the cardiac and oesophageal CPs, previously developed in Radboudumc, and started in 2013.

The first step was redefining and searching for evidence underneath the surgical, anaesthesiology and ICU protocols in the perioperative period. This was a multidisciplinary procedure, undertaken by the physician assistants, senior nurses, 'key' nurses and medical staff. ${ }^{20-27}$ Instead of a traditional 'day-to-day-care' plan for the surgical ward, an 'hour-to-hour' care plan had to be developed, including the PACU and ICU care. It was important to identify potential barriers and facilitators in these settings, in order to tailor the implementation strategy. ${ }^{28-31}$ An evidencebased implementation strategy according to Grol was used. ${ }^{32}$ Second, a unique variance report ('Radboud variance report'; Appendix 1) had to be incorporated and developed together with the CP. ${ }^{33}$ This Radboud model of variance report enables nurses, physician assistants and young residents to execute predefined actions in accordance with and within the preset boundaries of a variance protocol, without having to wait for approval of the responsible physician first (Dutch law and order for health care professionals BWBR0006251 chapter IV, article 35).

Until 2012, a surgical pancreas matrix for (peri)operative care was used at the surgical ward. The historical control group was treated according to this matrix including the surgical medical and nursing protocols without the variance report. In the PACU and ICU, these patients were treated according to different PACU and ICU protocols. This pancreas matrix was used as backbone for further multidisciplinary development of the CP. As part of the development and implementation strategy, a small group of key nurses responsible for other CPs reflected on the concepts of the pancreas CP and variance report as part of a Prepare-Act-Reflect (PAR) Cycle.

The pancreas CP had to be a continuum from admission to discharge from the hospital. Essential elements included restrictive intra-operative fluid use, strict pain control, early mobilization, early drain and tube removal and early enteral feeding. Post-operatively, early warning scores (EWS) are measured at least once during every 8 -h shift or more frequent, whenever indicated by the nurses, with strict directives for action by nurses according to the variance report. ${ }^{34}$

Patients with a malnutrition universal screening tool (MUST) score above 2 need an active feeding intervention according to the quality system of health care in the Netherlands. We decided that patients with a MUST above 2 should start with total parenteral nutrition (TPN) within $24 \mathrm{~h}$ after surgery. Publications on 
calorie deficit and enteral feeding or TPN after surgery in ICU patients often do not take into account malnutrition and MUST score $>2$. Our protocol prescribes that if the gastric tube can be removed, the patients need to start with oral/enteral feeding, and TPN needs to stop as soon as the oral intake of the patients is above $1000 \mathrm{kcal}^{22},{ }^{23}, 35-37$ TPN should be started on day 3 if patients had a MUST score of 1 and enteral feeding had not been started on day 3 . All patients with a gastroparesis without signs of sepsis or ileus on day 7 will be given a naso-jejunal tube by the gastroenterologist through the gastrojejunostomy and start enteral feeding. ${ }^{38}$ In contrast to ERAS-based protocols, deviations from the $\mathrm{CP}$ had to lead into prompt actions according to the variance report.

\section{Implementation of the $\mathbf{C P}$}

After informative meetings for medical and nursing staffs, including reflections on the positive aspects of previous $\mathrm{CPs}$, bedside training started on the surgical ward and PACU/ICU in 2014. Implementation of the pancreas CP would introduce an essential change in daily practice for most nurses, physician assistants and medical staff. The first step in teaching was getting acquainted to the $\mathrm{CP}$ vision that would result to one continuous multidisciplinary protocol. ${ }^{32}$ In nursing and medical staff meetings, updates of the project were discussed, and feedback was welcomed by the CP developers. During this teaching period, especially new PACU-specific aspects arose for the pancreas $\mathrm{CP}$, including new variance report criteria, and as an interactive process of PAR cycles, these criteria were incorporated in the pancreas $\mathrm{CP}$ during the development. In this try-out period, feedback was asked and given every 4 weeks during the multidisciplinary team meetings of the project. After 4 months of teaching and try-out period, it was concluded that it was feasible and safe to use the pancreas CP with the Radboud model variance report for patients during their entire clinical stay, including the PACU/ICU. With the completion of this implementation step, the pancreas CP was considered being implemented and our study on the use of the $\mathrm{CP}$ and variance report for all pancreaticoduodenectomy patients started on the first of September 2014, 18 months after the start of the development of the $\mathrm{CP}$, including many PAR cycles. Patients treated for other pancreas procedures than pancreaticoduodenectomy were considered candidates to have the benefits of the pancreas $\mathrm{CP}$ during their stay in PACU/ICU and ward, but were not included in this study. Protocol adherence was measured per pathway action. We considered protocol adherence if a deviation from the CP resulted in the correct action, according to the $\mathrm{CP}$, or if no action was needed and no action was started. No protocol adherence was defined as wrong actions or no actions if actions were needed. Deviations from the $\mathrm{CP}$ had to be described in the variance report or patient record.

\section{Design}

This is a pre-post design study. After the implementation of the pancreas $\mathrm{CP}$, patients treated according to the $\mathrm{CP}$ were compared with a historical control group of patients treated with standard perioperative care for pancreaticoduodenectomy according to the original pancreas matrix and monodisciplinary protocols and operated on between 2009 and 2012.

\section{End Points}

Primary endpoint was to determine the feasibility and safety, including incidence of post-operative complications, according to Clavien-Dindo classification, of the use the CP. Secondary endpoints were in length of stay (LOS) in-hospital, postoperative fluid balance, gastroparesis, protocol adherence to mobilization, drain removal, radiologic and surgical re-interventions, ICU readmission, hospital readmission and mortality rate.

\section{Statistics}

Continuous variables were described as median and interquartile range [IQR] and tested with the Mann-Whitney $U$ test. Differences in dichotomous variables were analyzed using the chi-squared test. Due to the exploratory nature of this study, and to increase the sensitivity to detect differences between groups, no correction for multiple testing was performed. With our convenience sample size of 95 patients in the CP group and 52 patients in the control group, our study had $80 \%$ power to demonstrate a $7 \%$ absolute reduction of post-operative complications. All statistical analyses were performed using SPSS version 20.01 for Windows (IBM, SPSS statistics, Chicago, IL, USA).

\section{Results}

\section{Development Results of the CP}

Nurses, physiotherapists, dieticians and medical staff specialized in pancreas surgery contributed to the development of the pancreas $\mathrm{CP}$ and the variance report. This resulted in a set-up of clear and safe boundaries in taking clinical treatment decisions and an upscaling system to consultation with a key nurse or senior staff members, if actions according to the variance report did not seem right.

First, the pancreas CP for medical and nursing decisions was written according to existing evidence-based protocols, best practices and guidelines. Finally, a multidisciplinary variance report was incorporated (Appendix Table 4: summary of the differences between $\mathrm{CP}$ and control surgery and Appendices 2 and 3: variance report).

For the analysis of the developmental process, we evaluated barriers and facilitators for protocol adherence. For this, 
interviews and questionnaires were used, focussing on possible barriers and facilitators for protocol adherence to the new CP. An important facilitator was the motivation of nursing and medical staff to ask for guidance and training in the use of this protocol. The most important barrier was that using the protocols was experienced as a time consuming processes of getting acquainted with the system, resulting in feelings of loss of autonomy for doctors and nurses. Key nurses together with medical leadership were essential for awareness, feedback and motivation during development, implementation and the use of the CP.

\section{Implementation Results of the CP}

First, the medical aspects of the CP were implemented on the ward followed by the nursing aspects. Because of the lack of experience with CPs, the care providers working on the PACU received more time for training and bedside teaching and started later with implementation. Key nurses at the surgical ward gave guidance and were partner for the key nurses of the PACU.

Evaluation after the implementation process was performed every 2 months during the first 6 months and after this period whenever needed. These evaluations resulted mostly in questions or new ideas for a change in the $\mathrm{CP}$ from the units or when less compliance was observed. The variance report was an important tool for evaluating compliance. When compliance of one of the CP domains was below $80 \%$, feedback was given by the key nurse or surgeon through focussed teaching sessions for nurses and residents.

After a period of 18 months, the pancreas CP was implemented and evaluation of protocol adherence was $80 \%$ for PACU/ICU periods and $60 \%$ for the surgical ward. The latter was mainly influenced by a low compliance to drain removal $(<50 \%)$. According to the pancreas $\mathrm{CP}$, drain removal was allowed if amylase level in the drain was below $500 \mathrm{U} / 1$ and volume below $200 \mathrm{ml} /$ day. Deviations turned out to be primarily a system problem of postponing drain removal during weekends. After recognition of this system problem, an active policy started and protocol adherence on this item improved to above $80 \%$.

Following the implementation, in September 2014, the outcome study of the pancreas CP was started (Fig. 1 implementation flowchart).

\section{Clinical Outcomes}

Between September 2014 and September 2016, in total, 95 elective consecutive pancreaticoduodenectomy patients were treated within the pancreas CP. Semi-acute pancreaticoduodenectomies (for bleeding tumours) and other types of resections (e.g. total pancreatic resections or pancreaticoduodenectomies with resection of a secondary colorectal tumour) were no part of the study. A cohort of 52 consecutive elective pancreaticoduodenectomy patients treated before the $\mathrm{CP}$ implementation period between 2009 and 2012 was identified as historical control group. Their perioperative treatment had been according to the underlying matrix protocol that was used as base for the development of the CP. Three surgeons in the pre-CP period operated on the pancreaticoduodenectomy patients. Results between these surgeons did not differ, and perioperative care was regulated by protocols. These surgeons were also responsible for pancreas surgery in the CP period.

Baseline characteristics between the two groups were not significantly different, apart from a higher number of CP patients receiving portal vein resection or celiac trunk/superior mesenteric artery (SMA) vessel exploration (Table 1).

\section{Intra-operative Data}

The median intra-operative amount of fluids administered was $3900 \mathrm{ml}$ [IQR 3000-4600] in the CP patients versus $5200 \mathrm{ml}$ [IQR 4000-6000] in the control group $(p<0.001)$. Postoperative fluid balance and fluid balance on day 1 postoperative were also significantly lower in the $\mathrm{CP}$ group versus the control group ( $p<0.001$; Table 2$)$. Although more portal vein resections and celiac trunk and explorations along the SMA were performed, blood loss was less in the CP patients: $755 \mathrm{ml}$ [IQR 500-1100] versus $1303 \mathrm{ml}$ [IQR 656-2402] $(p<0.001$, Table 2$)$.

\section{Post-operative Data}

Adherence of pain and hemodynamic interventions according to the variance report was $100 \%$ at the PACU/ICU, and a step-up approach regarding pain control was adequately used according to CP protocol. Hemodynamic interventions in accordance with the variance report were not needed and not started in $17 \%$ of the $\mathrm{CP}$ patients, and $57 \%$ of the CP patients needed an extra hemodynamic intervention which was subsequently started according to the CP protocol. In total, $26 \%$ of the patients were treated with vasopressors on arrival in the PACU/ICU, which could be reduced during their stay. Significantly more CP patients were swing mobilized within $24 \mathrm{~h}$ compared with the control group, respectively, 83 versus $19 \%, p=0.001$. Especially poor pain control and patients' feelings of weakness, early after the operation, were recorded as reasons not to start swing or mobilization at the surgical ward. Trigger for complications was the EWS; in $32 \%$ of the patients in the CP group, the EWS was above 3. Interventions on a high EWS were adequate and according to the variance report $>95 \%$ of the patients.

Considering clinical outcome, major complications according to the Clavien-Dindo classification grade 3 or more occurred less frequently ( 13 vs $27 \%, p=0.02$ ) in the CP group, compared to the control group. ${ }^{39}$ One patient had a ClavienDindo $4 \mathrm{~b}$ complication as a result of pancreatic leakage complicated by sepsis with EWS $>6$ on day 7 and hemorrhagic bleeding on day 14 in the CP group. This complication was successfully treated by radiologic coiling of the gastroduodenal artery and splenic artery. 


\section{Short Cycle Act and Reflect meetings}

input and feed back in 2-4monthly meetings and close e-mail contact
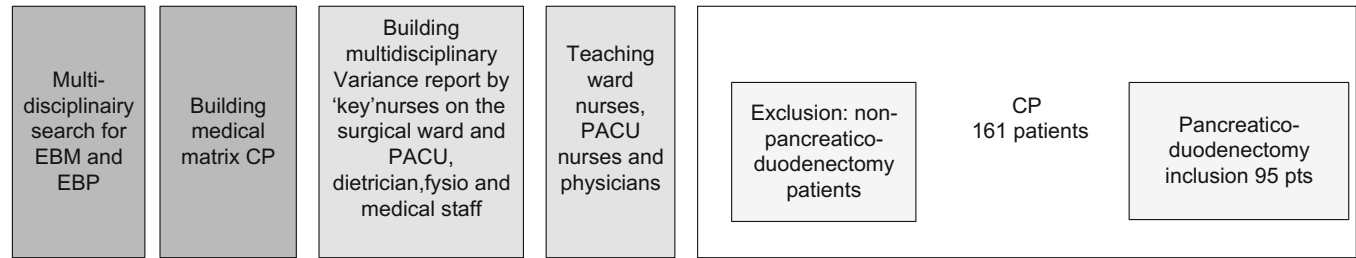

Development of the Radboud variance report and $\mathrm{CP}$ for pancreaticoduodenectomy

training in use of $\mathrm{CP}$ and variance report

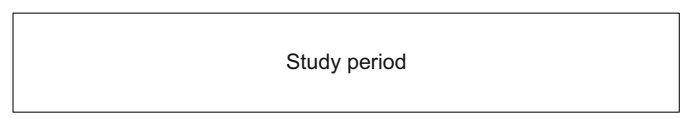

strategy development
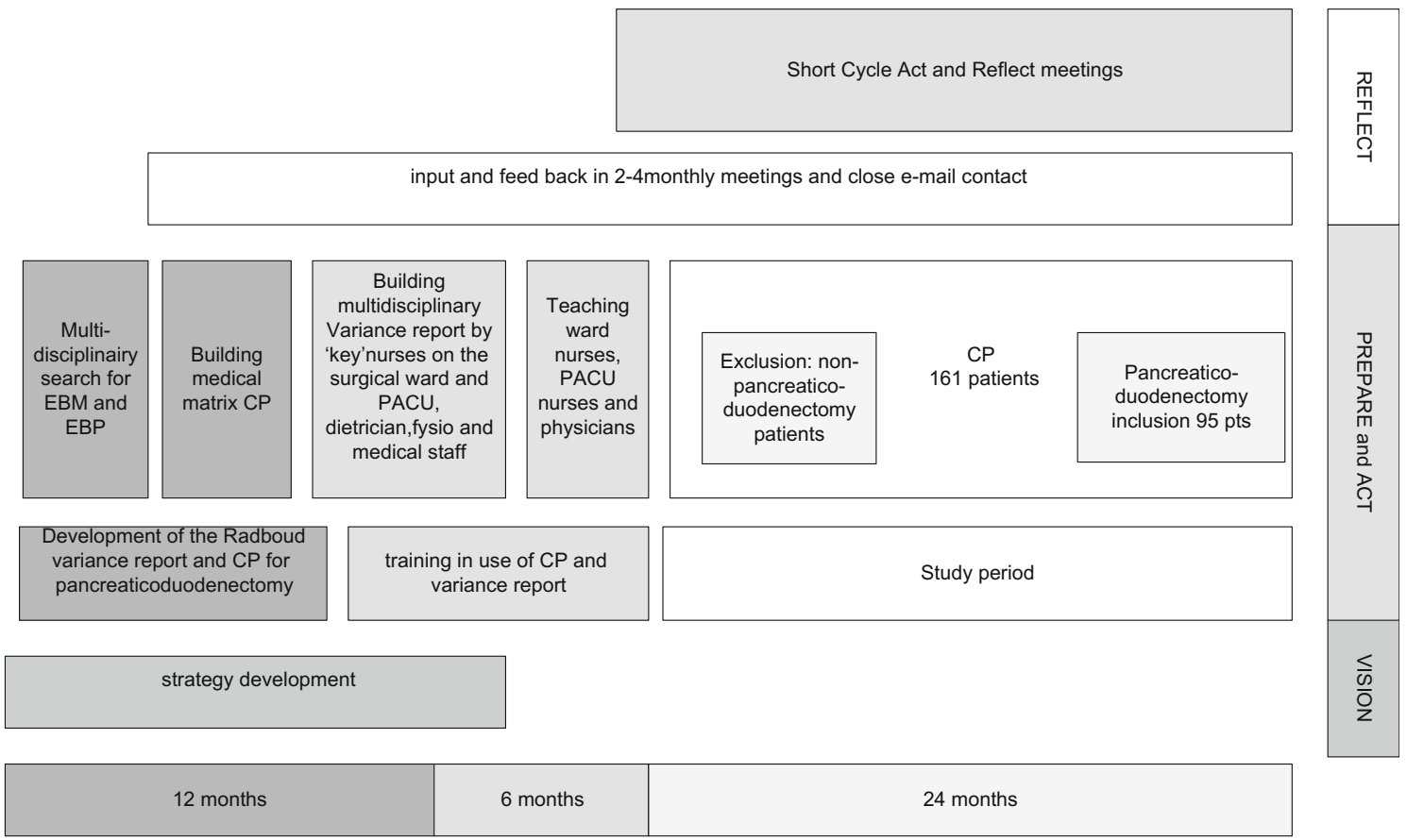

Fig. 1 Implementation of pancreas $\mathrm{CP}$ and study flowchart

Less patients suffered from gastroparesis grades B and $\mathrm{C}$ in the $\mathrm{CP}$ group compared to the control group, 9 versus $62 \%, p<0.001$, as were radiologic interventions: 11 versus $27 \%, p=0.04$. In the control group, the gastric tube was not removed when production was reduced but was left in place and blocked and could be removed if after measurement of retention after 8 and $16 \mathrm{~h}$, it was less than $100 \mathrm{ml}$ per $8 \mathrm{~h}$. Pancreatic leakage and chylus leakage, readmission to ICU and readmission to hospital did not significantly differ between the $\mathrm{CP}$ group and control group. Median times to drain removal were also not influenced. The mortality rate was low and not different between groups (Table 3).

\section{Discussion}

This study illustrates that development of a CP for pancreaticoduodenectomy is an iterative multidisciplinary process, starting with a dynamic protocol with improvements through PAR cycle evaluation and change moments. Implementation of the pancreas $\mathrm{CP}$ in all units involved in the entire (peri-) operative process (OR, PACU/ICU/surgical ward) took 18 months. Process evaluation of the prospective $\mathrm{CP}$ group revealed that protocol adherence was successfully achieved in $>80 \%$ for most of the criteria throughout the clinical stay. Comparison of both cohort groups on main clinical outcomes showed that major complications according to the Clavien-
Table 1 Baseline characteristics of pancreas $\mathrm{CP}$ and control groups of pancreaticoduodenectomy

\begin{tabular}{llll}
\hline & Clinical pathway, $N=95$ & Control, $N=52$ & $P$ \\
\hline Age, median (IQR) & $66(57-72)$ & $66(58-72)$ & 0.98 \\
Male, $n(\%)$ & $56(58.9)$ & $35(67.3)$ & 0.26 \\
Stent/(PTC) percutaneous drainage, $n(\%)$ & $59(61.5)$ & $28(53.8)$ & 0.34 \\
Pulmonary comorbidity, $n(\%)$ & $13(13.7)$ & $4(7.7)$ & 0.52 \\
Cardial comorbidity, $n(\%)$ & $13(13.7)$ & $10(19.2)$ & 0.62 \\
Vascular comorbidity, $n(\%)$ & $29(30.5)$ & $16(30.8)$ & 0.80 \\
Diabetes, $n(\%)$ & $21(22.1)$ & $16(31.4)$ & 0.4 \\
Preoperative chemotherapy, $n(\%)$ & $4(4.2)$ & 0 & $<0.001$ \\
Portal vein resection, $n(\%)$ & $20(21.1)$ & $1(1.9)$ & \\
Celiac trunk/SMA exploration, $n(\%)$ & $6(6.3)$ & 0 & \\
\hline
\end{tabular}

$I Q R$ first and third interquartile range, $P T C$ percutaneous transhepatic cholangiography, SMA superior mesenteric artery 
Table 2 Intra-operative results of pancreas $\mathrm{CP}$ and control groups of pancreaticoduodenectomy

\begin{tabular}{|c|c|c|c|}
\hline Fluid and vasopressor management & Clinical pathway, $N=95$ & Control, $N=52$ & $P$ \\
\hline Intra-operative fluids (ml), median (IQR) & $3900(3000-4600)$ & $5200(4000-6000)$ & $<0.001$ \\
\hline Fluid balance, at the end of the procedure, median (IQR) & $405(-107$ to 833$)$ & $1926(1253-2818)$ & $<0.001$ \\
\hline Intra-operative blood loss, median (IQR) & $755(500-1100)$ & $1303(656-2402)$ & $<0.001$ \\
\hline Intra-operative vasopressor use, $n(\%)$ & $94(99)$ & $48(92)$ & 0.22 \\
\hline
\end{tabular}

Dindo classification grade 3 or more and hospital LOS in the CP group were significantly lower compared to the control group. In addition, implementation of the $\mathrm{CP}$ was associated with a reduction of gastroparesis, an improved post-operative fluid balance, and patients in the $\mathrm{CP}$ group were more likely to receive early mobilization and adequate actions on EWS above 3. These data illustrate that implementation of a CP in this specific group of patients is feasible, safe and likely to be beneficial for the patient.

Analyzing reasons not to follow the variance report was part of this study. Human factors were often reasons for deviation from the report, for example, insecurity of young professionals on decisions leading to postponing gastric tube removal. The prevention of gastroparesis is part of a very active PAR cycle in the CP. Nurses, young doctors and patients want

Table 3 Post-operative data of pancreas CP and control groups of pancreaticoduodenectomy

\begin{tabular}{|c|c|c|c|}
\hline & $\begin{array}{l}\text { Clinical } \\
\text { pathway, } \\
N=95\end{array}$ & $\begin{array}{l}\text { Control, } \\
\quad N=52\end{array}$ & $P$ \\
\hline Post-operative PACU, $n(\%)$ & $81(85)$ & $29(55)$ & 0.002 \\
\hline $\begin{array}{l}\text { Mobilization swing, } \\
\text { according to protocol } \\
\text { (within } 24 \mathrm{~h}) n(\%)\end{array}$ & $78(83)$ & $10(19)$ & 0.02 \\
\hline $\begin{array}{l}\text { Mobilization out of bed in } \\
\text { days, median (IQR) }\end{array}$ & $2(1-2)$ & $2(2-3.3)$ & 0.001 \\
\hline \multicolumn{4}{|l|}{ Gastroparesis (ISGPS): $n(\%)$} \\
\hline $\begin{array}{l}\text { - Type A } \\
\text { - Type B }\end{array}$ & $\begin{array}{l}20(21) \\
7(7)\end{array}$ & $\begin{array}{l}15(29) \\
18(35)\end{array}$ & $<0.001$ \\
\hline - Type C & $2(2)$ & $14(27)$ & \\
\hline Pancreas leakage, $n(\%)$ & $12(13)$ & $5(10)$ & 0.82 \\
\hline Drain in situ (days), median (IQR) & $6(4-10)$ & $7(5-12)$ & ns \\
\hline \multicolumn{4}{|l|}{ Clavien-Dindo classification $n(\%)$} \\
\hline $\begin{array}{l}3 \mathrm{a} \\
3 \mathrm{~b}\end{array}$ & $\begin{array}{l}9(10) \\
1(1)\end{array}$ & $\begin{array}{l}9(19) \\
4(8)\end{array}$ & 0.02 \\
\hline $4 \mathrm{~b}$ & $1(1)$ & 0 & \\
\hline 5 & $1(1)$ & 0 & \\
\hline Radiologic reintervention, $n(\%)$ & $10(11)$ & $14(27)$ & 0.04 \\
\hline Relaparotomy, $n(\%)$ & $3(3)$ & $4(8)$ & 0.01 \\
\hline Readmission ICU, $n(\%)$ & $7(7)$ & $7(14)$ & ns \\
\hline Readmission hospital, $n(\%)$ & $12(13)$ & $9(18)$ & ns \\
\hline $\begin{array}{l}\text { LOS in-hospital (days), } \\
\text { median (IQR) }\end{array}$ & $10(8-15)$ & $13(10-18)$ & 0.02 \\
\hline 30-day mortality, $n(\%)$ & $1(1)$ & 0 & ns \\
\hline 90-day mortality, $n(\%)$ & $2(2)$ & $1(2)$ & \\
\hline
\end{tabular}

to prevent discomfort for the awake patient while repositioning the tube, even if early removal is according to protocol. The action was a team reflection on the discomfort of a needless gastric tube for too long and, as a result, delay in starting early oral nutrition and well-being.

Postponing early mobilization because of patients' pain or weakness did occur. In all situations, the iterative process of repeated and specific education was important to explain the reasons behind the $\mathrm{CP}$ and guidance.

Considering the diverse landscape of CPs and surgical care plans, it is difficult to compare the different studies. In studies, related to implementation of CPs, not all hospital wards involved in the clinical process (like PACU/ICU) were included, which negatively influences the continuous care process for the patient. Also different treatment regimes make reliable comparison and evaluation of different CPs difficult. Regarding the available studies, we found only studies not covering the whole clinical stay, excluding parts of the postoperative period. In these studies usually some specific aspects like ERAS, drain and gastric tube removal were addressed. ${ }^{18}$ A standardized care plan for pancreaticoduodenectomy patients was retrospectively studied in another study focussing on predictors of LOS in-hospital. ${ }^{15}$ Specific ERAS pathways, without PACU/ICU periods involved, focussed on in-hospital LOS, outcome mortality and morbidity. While these were unchanged, measurement of protocol adherence was not part of the study. ${ }^{16}$ Braga et al. evaluated the compliance to the enhanced recovery protocol and concluded that patients with low compliance had a higher incidence of complications. ${ }^{40}$

Our results are in pursuance of previous studies that showed that a CP or standardized care plan for pancreaticoduodenectomy patients resulted in an earlier start of solid enteral feeding and a shorter hospital LOS and less readmissions. Importantly, protocol adherence to predefined targets has not been part of these studies as was analysis of the reasons not following the protocol and its association to outcome.

Comparing our study to these studies, a similar effect on reduction of complications, hospital LOS, readmissions, gastroparesis, time to enteral feeding and time to mobilization was found. Our present study also illustrates that it is feasible to implement a CP that covers the entire clinical admission, applying different targets of the various involved units (e.g. focus on hemodynamic and respiratory vital parameters at the PACU/ICU, versus focus on EWS and ERAS criteria at the 
surgical ward). Nurses were also able to start adequate therapy in accordance with the variance rapport when EWS deviated from the target. Moreover, new to the other studies is that this study, via the variance report method, exposed the barriers and facilitators of $\mathrm{CP}$ adherence. In addition, these two monthly formal meetings to evaluate variance report deviations and their barriers and facilitators enabled us to discriminate the difference of loss of compliance to a protocol due to complicated discourse of operations, versus loss of professional adherence to the CP protocol.

The current study has several limitations. Most importantly, this is a single-centre pre-post-intervention study. The intensity and duration to develop the $\mathrm{CP}$, as well as the implementation process, limit the feasibility of using other study designs. In addition, the historical group was not formally matched, which, together with the fact that no randomization was carried out, induces a higher risk of confounding factors. No relevant differences in patient characteristics between the different study periods were observed. However, the case load per surgeon increased, which could be considered as a possible confounding factor. We considered the development of a $\mathrm{CP}$ as the most appropriate intervention to re-schedule the process. Prospective complication registration was part of the daily supervised perioperative care as well as the discharge procedure in both groups. Moreover the prospective database on outcome and complications of the control group (2009-2012) served as a document to identify barriers and facilitators for building the CP. Furthermore, no relevant changes in other procedures, staffing levels, technical infrastructure or other major changes that could influence patient management occurred, and during the whole study period, there were no changes in interventions that are known to influence morbidity or mortality in the ICU such as strict glucose regulation, early goal-directed therapy, use of corticosteroids, prone positioning and low tidal volume ventilation. Second, no a priori power calculation was carried out, implying that the risk for a type 1 or 2 error has not been overcome. Using our convenience sample, we did calculate that our study has $80 \%$ power to demonstrate a $7 \%$ change in complication rate, while we observed that the complication rate halved. Nevertheless, the sample size of the study and the discussed design issues should make us aware of the possible overestimation of the outcome differences. In contrast, this does not necessarily apply for the process analysis part. As no comparison of the $\mathrm{CP}$ group was made to the control group, the conclusions of the process analysis merely indicate that $\mathrm{CP}$ development, implementation and high level of adherence to such a $\mathrm{CP}$, throughout all units involved in the perioperative process, are feasible within a relative short period and up to a high standard.

\section{Lessons Learned}

This study shows us, in line with the implementation of our cardiac surgery $\mathrm{CP}$ and oesophageal surgery $\mathrm{CP},{ }^{41}$ that it is feasible to develop and implement a $\mathrm{CP}$ for pancreaticoduodenectomy procedures for all involved units like the PACU/ICU and surgical ward through the entire clinical perioperative period. In all units, the CP targets need to be aligned and the use of a variance report discriminates complication-related to failure of professional adherence. Implementation is an iterative process that takes time to become comfortable in use for all involved units. Key nurses together with medical leadership were essential for awareness, feedback and motivation during development, implementation and the use of the $\mathrm{CP}$.

\section{Future Perspectives}

In order to overcome the methodological drawbacks of this study and to validate the CP methods, a multicenter steppedwedged cluster randomized controlled trial would be ideal. However, due to the complexity of the implementation and intervention with barrier and facilitator analysis in different hospitals and units, interpretation of the results will be difficult. Exploring the validity of similar CPs is in line with the need for quality assurance of standardized treatment regimes with high protocol adherences.

For the near future, continuous monitoring, wearables and electronic medical data recording with pop-up facilities warning medical and nursing staff for deviations from the $\mathrm{CP}$ will likely be of help in building more complex pathways. Possibly, patients with high comorbidity will be able to follow their personalized clinical pathway (pCP) with the help of dedicated staff.

\section{Conclusion}

The use of the CP was associated with a reduction of perioperative morbidity. Essential new tools include a variance report analysis, scheduled barrier and facilitator analyses and the iterative PAR cycle protocol development, performed by a multidisciplinary team. Development, implementation and use of a CP throughout the hospital stay for patients undergoing pancreaticoduodenectomy are a multistep procedure in which we showed that this is feasible and safe.

Acknowledgements This study was conceived and designed by MvdK, FB-V, HC, MvdB, HvdH and PP. MvdK and MvdB performed the data collection. Data analysis and discussion, together with the interpretation of the results, were a mutual effort of all authors. MvdK, MvdB, PP and KvL drafted the manuscript, and all authors contributed substantially to its revision. All authors take responsibility for the paper as a whole and agree to be accountable for all aspects of the work.

\section{Compliance with Ethical Standards}

Conflict of Interest The authors declare that they have no conflict of interest. 


\section{Appendix 1}

Table 4 Similarities and differences between clinical pathway and control period

\begin{tabular}{|c|c|c|}
\hline & Clinical pathway & Control \\
\hline \multirow{5}{*}{$\begin{array}{l}\text { Outpatient } \\
\text { clinic }\end{array}$} & Tumour board treatment advice (PACON) & Tumour board treatment advice (PACON) \\
\hline & Oral and written patient information & Oral patient information \\
\hline & $\begin{array}{l}\text { Dietician contact: MUST screening tool, nutrition advice and if needed } \\
\text { supplemental feeding oral or enteral } \\
\text { Frailty screening tool }\end{array}$ & Dietician contact if needed supplemental feeding oral or enteral \\
\hline & Medication verification & \\
\hline & Training advice: home trainer use, 1 -h walking per day & \\
\hline \multirow{16}{*}{$\begin{array}{l}\text { Surgical } \\
\text { ward }\end{array}$} & Use of ERAS protocol & Use of ERAS protocol \\
\hline & Preoperative lanreotide ${ }^{\mathbb{R}}$ & Preoperative lanreotide ${ }^{\mathbb{R}}$ \\
\hline & Thrombosis prophylaxis nadroparine ${ }^{\mathbb{R}} 5700 \mathrm{E}$ & Thrombosis prophylaxis nadroparine ${ }^{\circledR} 2850 \mathrm{E}$ \\
\hline & $\begin{array}{l}\text { 6:00 day of operation: last preop or clear liquid intake, anti-thrombosis } \\
\text { compression stockings. }\end{array}$ & \\
\hline & $\begin{array}{l}\text { Pain management and control according to protocol together with pain } \\
\text { service team }\end{array}$ & Pain management together with pain service team \\
\hline & $\begin{array}{l}\text { Early warning score once per } 8 \mathrm{~h} \text { and whenever indicated together with } \\
\text { actions by nurses }\end{array}$ & $\begin{array}{l}\text { Early warning score once per } 8 \mathrm{~h} \text { and whenever indicated action } \\
\text { by resident }\end{array}$ \\
\hline & $\begin{array}{l}\text { Patient communication between doctors, nurses and handover situations } \\
\text { according to Reason, Story, Vital Signs and Plan (RSVP) }\end{array}$ & $\begin{array}{l}\text { Patient communication between doctors, nurses and handover } \\
\text { situations not specified }\end{array}$ \\
\hline & Mobilization after surgery: swing and out of bed within $24 \mathrm{~h}$ & Mobilization after surgery: swing and out of bed within $24 \mathrm{~h}$ \\
\hline & Gastric tube: if production $<200 \mathrm{ml}$ in $12 \mathrm{~h}$, remove tube & $\begin{array}{l}\text { Gastric tube: if production is reduced, start clamp tube and } \\
\text { remove if retention is }<100 \mathrm{ml} \text { in } 8 \mathrm{~h} \text { (after two consecutive } \\
\text { periods of } 8 \mathrm{~h} \text { ) }\end{array}$ \\
\hline & Drain removal if production $<200 \mathrm{ml}$ and amylase $<500 \mathrm{U} / 1$ per day & $\begin{array}{l}\text { Drain removal if amylase }<500 \mathrm{U} / 1 \text { per day and operating } \\
\text { surgeon agrees }\end{array}$ \\
\hline & Nutrition: MUST $>2$, start TPN on day 1 post-operative & $\begin{array}{l}\text { Nutrition: enteral feeding will start on day } 1 \text { if the patient has a } \\
\text { jejunostomy. Oral fluids according to ERAS }\end{array}$ \\
\hline & MUST $=1$ : if gastric tube has not been removed on day 3 , start TPN & If no enteral intake is possible on day 6 , TPN has to start on day 7 \\
\hline & $\begin{array}{l}\text { All patients: if the gastric tube cannot be removed because of } \\
\text { gastroparesis on day } 7 \text { without signs of sepsis or ileus: placement of a } \\
\text { jejunal tube through the gastrojejunostomy by the gastroenterologist } \\
\text { and start enteral feeding }\end{array}$ & \\
\hline & Glucose control & Glucose control \\
\hline & Discharge criteria & Discharge criteria not specified \\
\hline & Use of the variance report if actions are not according to protocol. & \\
\hline \multirow{6}{*}{$\begin{array}{l}\text { Operating } \\
\text { room }\end{array}$} & Use of ERAS protocol & Use of ERAS protocol \\
\hline & Pain control by epidural catheter & Pain control by epidural catheter \\
\hline & Central venous line in the vena jugularis, if indicated $\mathrm{PiCCO}$ & \\
\hline & $\begin{array}{l}\text { Antibiotic prophylaxis } 15-60 \text {-min pre-incision. Cefazoline } e^{\circledR} \text { and } \\
\text { metronidazole }{ }^{\mathbb{R}} \text {. If a stent or percutaneous transhepatic drain has been } \\
\text { placed in the ductus choledochus, use piperacillin/tazobactam }{ }^{\circledR} \text { as } \\
\text { prophylaxis. }\end{array}$ & $\begin{array}{l}\text { Antibiotic prophylaxis } 15-60-\text { min pre-incision. Cefazoline }{ }^{\circledR} \text { and } \\
\text { metronidazole }{ }^{\circledR} \text {. Otherwise if indicated by the surgeon }\end{array}$ \\
\hline & Target post-operative fluid balance between 0 and $500 \mathrm{ml}$ & Post-operative fluid balance not specified but according to ERAS \\
\hline & $\begin{array}{l}\text { Handover to PACU team members by surgeon and anaesthesiologist } \\
\text { according to RSVP }\end{array}$ & Handover to PACU team members by anaesthesiologist \\
\hline \multirow[t]{5}{*}{$\mathrm{PACU} / \mathrm{ICU}$} & $\begin{array}{l}\text { Entrance in PACU: every } 15 \mathrm{~min} \text { : RR and heart rate control until stable, } \\
\text { than every } 30 \text { min RR and pulse }\end{array}$ & $\begin{array}{l}\text { Entrance in PACU: every } 15 \text { min: RR and pulse control until } \\
\text { stable than every } 30 \text { min RR and pulse }\end{array}$ \\
\hline & $\begin{array}{l}\text { Continuation of antibiotics will be part of the sign-out procedure after } \\
\text { surgery }\end{array}$ & Continuation of antibiotics at the decision of the surgeon \\
\hline & Normothermia $\left(>36.0^{\circ} \mathrm{C}\right)$, Bair Hugger or heating system if necessary & $\begin{array}{l}\text { Normothermia }\left(>36.0^{\circ} \mathrm{C}\right) \text {, Bair Hugger or heating system if } \\
\text { necessary }\end{array}$ \\
\hline & Every hour (1st until 24th hour): & Every hour (1st until 24th hour): \\
\hline & $\begin{array}{l}\text { Respiratory status after extubation: saturation, respiratory frequency, } \\
\text { coughing and deep breathing exercises }\end{array}$ & $\begin{array}{l}\text { Respiratory status after extubation: saturation, respiratory } \\
\text { frequency, coughing and deep breathing exercises }\end{array}$ \\
\hline
\end{tabular}


Table 4 (continued)

Clinical pathway

Hemodynamics: heart rhythm, heart frequency, RR, $\mathrm{ScvO}_{2}$ (if indicated).

Excretions: urine, drain, gastric tube

Temperature

Pain and sedation: NRS pain score

RASS and CAM ICU

Mean arterial pressure (MAP) between 70 and $100 \mathrm{mmHg}$ and heart frequency between 60 and 90 per minute. Different targets than the $\mathrm{CP}$ prescribe possible after approval of the supervising anaesthesiologist .

MAP should be above $70 \mathrm{mmHg}$ : if below, start norepinephrine.

iv fluids: ERAS protocol

Balance between 0 and $+500 \mathrm{ml} / 24 \mathrm{~h}$

Urine production has to be above $0.5 \mathrm{ml} / \mathrm{kg} / \mathrm{h}$. Protocol 'oliguria PACU'

First choice of inotropics: dobutamine ${ }^{\circledR}$

Stress ulcer prophylaxis pantoprazole ${ }^{\circledR} 1 \mathrm{dd} 40 \mathrm{mg}$ iv/po

Nausea and vomiting:

3/day $4 \mathrm{mg}$ ondansetron ${ }^{\circledR}$ iv (maximum until $36 \mathrm{~h}$ after surgery)

3 /day metoclopromide ${ }^{\circledR} 3$ /day $10 \mathrm{mg}$ iv (3/day $5 \mathrm{mg}$ iv when kidney function reduced) (cave QT time)

Anti-thrombosis prophylaxis nadroparine ${ }^{\circledR}$ 5700IE

Mobilization according to protocol: starts within $24 \mathrm{~h}$

Gastric tube: see CP surgical ward

Drain: 2 abdominal drains

Drain production control every hour: aspect and volume, $100-200 \mathrm{ml} / \mathrm{h}$. If production $>200 \mathrm{ml} / \mathrm{h}$ or $>400 \mathrm{ml} / 4 \mathrm{~h}$, contact surgeon

Electrolyte control and interventions

Glucose regulation: normoglycaemia (glucose 5.0-10.0 mmol/l)

Discharge criteria: handover procedure according to RSVP, vital signs accepted by the surgical ward.

Use of the variance report if actions are not according to protocol.
Control

Hemodynamics: heart rhythm, heart frequency, RR, $\mathrm{ScvO}_{2}$ (if indicated).

Excretions: urine, drain, gastric tube

Temperature

Pain and sedation: NRS pain score

RASS

Mean arterial pressure (MAP) targets need approval of the supervising anaesthesiologist.

Urine production has to be above $0.5 \mathrm{ml} / \mathrm{kg} / \mathrm{h}$. Protocol 'oliguria PACU'

First choice of inotropics: supervising anaesthesiologist

Stress ulcer prophylaxis pantoprazole ${ }^{(\mathbb{R}} 1 \mathrm{dd} 40 \mathrm{mg}$ iv/po

Nausea and vomiting:

If indicated: $3 /$ day $4 \mathrm{mg}$ ondansetron ${ }^{\mathbb{R}}$ iv

If indicated: 3 day metoclopromide ${ }^{\mathbb{R}} 3$ day $10 \mathrm{mg}$ iv (3/day $5 \mathrm{mg}$ iv when kidney function reduced) (cave QT time)

Anti-thrombosis prophylaxis nadroparine ${ }^{\circledR} 2850$ IE

Gastric tube

Drain: 2 abdominal drains

Drain production control every hour: aspect and volume, $100-200 \mathrm{ml} / \mathrm{h}$. If production $>200 \mathrm{ml} / \mathrm{h}$ or $>400 \mathrm{ml} / 4 \mathrm{~h}$, contact surgeon

Electrolyte control and interventions

Glucose regulation: normoglycaemia (glucose 5.0-10.0 mmol/l)

Discharge criteria according to PACU 


\section{Appendix 2}

\begin{tabular}{|c|c|c|c|c|c|c|c|c|c|c|c|c|c|c|c|}
\hline \multicolumn{6}{|c|}{ Sticker patiënt } & \multicolumn{8}{|c|}{$\begin{array}{l}\text { CP Pancreaticoduodenectomy (Whipple, total pancreasresection and if indicated for other pancreassurgery) } \\
\text { DAy } 1\end{array}$} & & \\
\hline \multirow{2}{*}{\multicolumn{8}{|c|}{ 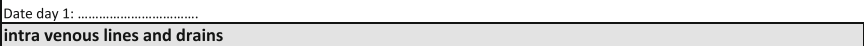 }} & & & & & & & & \\
\hline & & & & & & & & D & $\mathrm{E}$ & $\mathbf{N}$ & Nutrition & & Variance observed & & Intervention \\
\hline \multirow{2}{*}{$\square P_{p}$} & Perip & heral & infusion (NaCl 0,9\%) (1): ....... m//h & $\square$ & Drains (1): & \multirow{5}{*}{$\square$} & \multirow{5}{*}{$\begin{array}{l}\text { Diabetes?Follow glucoseprotocol (Q } \\
\text { portal). Beware of infusion protocol for } \\
\text { patients without oral intake. }\end{array}$} & \multirow[b]{2}{*}{$\square$} & \multirow[b]{2}{*}{ c } & \multirow{2}{*}{$\square$ St: } & \multirow{2}{*}{$\begin{array}{l}\text { Start oral intake: }(500 \mathrm{~m} / \mathrm{day} \text { clear } \\
\text { fluids/day) }\end{array}$} & \multirow[b]{2}{*}{$\square$} & \multirow{2}{*}{ gastric tube removed } & & \multirow{2}{*}{$\begin{array}{l}\text { Start fluids and if possible 6-8x } \\
\text { /day small light meals }\end{array}$} \\
\hline & & heral & & $\square$ & Drains (2): & & & & & & & & & & \\
\hline$\square$ & \multicolumn{3}{|c|}{ Peripheral infusion (NaCl 0,9\%(2): :...... m//h } & $\square$ & Bladdercatheter: & & & $\square$ & $\square$ & $\square$ & MUST-score & \multirow[t]{2}{*}{$\square$} & MUST 2 & 口 & $\begin{array}{l}\text { Start TPN according to nutrition prot-oco } \\
\text { and judge refeeding chance }\end{array}$ \\
\hline \begin{tabular}{|c|c|c|c|}
$\square$ \\
\end{tabular} & & alver & nous cathetere(2) $\ldots \ldots \ldots . . . \mathrm{m} / \mathrm{h}$ & 口 & Gastri tube: & & & $D$ & $\mathrm{E}$ & $\mathbf{N}$ & Woundcare & & Variance observed & & Intervention \\
\hline 口 & & urat & 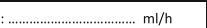 & $\square$ & Oxygen: ...................... It $/ \mathrm{min}$ & & & $\square$ & 口 & $\square$ & Control gastric tube:production and color & $\square$ & No gastric tube & 口 & Stop control \\
\hline $\mathrm{D}$ & $E$ & $\mathbf{N}$ & Vital Signs & & riance observed & & Intervention & T. & إ & 0 & care and control CVC and peripheral & $\square$ & surrounding red skin or infiltrate & D & CVC sepsis or infusion protocol \\
\hline$\square$ & $\square$ & $\square$ & Control vitale signs acc. MEWS & 口 & MEWS-Score $>3$ & $\square$ & Interventions acc. MEWS-protocol & ] & (4) & ${ }^{\circ}$ & i.v. catheters & $\omega^{4}$ & 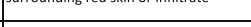 & J & We \\
\hline$\square$ & $\square$ & $\square$ & Bloodpressure & $\square$ & Syst $<90$ and normal pulse & $\square$ & $\begin{array}{l}1 \times 250 \mathrm{ml} \mathrm{NaCl} 0,9 \% \text { in } 15 \mathrm{~min} \text {. If needed } \\
\text { repeat } 1 \mathrm{x} \text {. No effect contact doctor }\end{array}$ & $\square$ & $\square$ & $\square$ & Epidural introduction skin control & $\square$ & swollen skin, red, infiltrate & 口 & Contact painteam \\
\hline & & & & 田 & Sat $91-96 \%$ & $\square$ & More $\mathrm{O}_{2}$ if needed up to $5 \mathrm{LO}_{2}$ & ( & & & Wounddrain skin introductionL $1 x$ & $\square$ & Leakage & 口 & $3 x$ day care and bandage \\
\hline$\square$ & $\square$ & $\square$ & respiration/saturation & $\Delta$ & pal $91-90 \%$ & $\square$ & No effect contact doctor & 崖 & & & & 品 & & & \\
\hline & & & & $\square$ & Sat $<91 \%$ & $\square$ & $\begin{array}{l}\text { Discuss with consultant if NRB-mask is } \\
\text { needed and discuss MCU }\end{array}$ & $\square$ & & & Abdominal wound care & $\square$ & No leakage and no infection & $\square$ & $1 x$ day woundcare \\
\hline & & & & ㅁ & Irr. pulse $1^{\text {ste }}$ time & $\square$ & call doctor and uptain an ECG & & & & & $\square$ & Leakage and signs of infection & ㅁ & Woundplan \\
\hline$\square$ & $\square$ & 口 & Pulse & 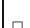 & Irr. pols (after the first time and high or lower & & contact doctor & $\square$ & 口 & $\square$ & Cô fixation drain en gastri tube & $\square$ & not sufficient or traction drain or gastric tubeMH & $\square$ & Fixation acc to protocol \\
\hline & & & & $\square$ & RR than normal for the patient & $\square$ & contact doctor & D & $\mathrm{E}$ & $\mathbf{N}$ & Other & & riance observed & & tervention \\
\hline 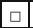 & $\square$ & $\square$ & Temp & $\square$ & Temp $\geq 39,0^{\circ} \mathrm{C}$ and/or shiffering & $\square$ & contact doctor and take bloodcultures & & & & Call PACU if patient will be & I & Patiënt stays at PACU or goes to & ח & Red is free for other natient \\
\hline D & $\mathrm{E}$ & $\mathbf{N}$ & Input/Output & & riance observed & & Intervention & (4) & & & transfered to the ward at 11 hours & ㄴ & IC/MC & ए & bea is tree tor otner patient \\
\hline إ & ( & م & fluidintake $24 \mathrm{~h}$ : $\max .2,5 \mathrm{~L}$ ( & $\square$ & $\begin{array}{l}\text { Balance in } 24 \mathrm{~h}>1 \text { liter positive or }>1 \text { liter } \\
\text { negative }\end{array}$ & $\square$ & contact doctor and adjust iv infusion & إ & & & $\begin{array}{l}\text { Venouspunction ( PACU): KNK, Hb, } \\
\text { Ht.ASAT_ALAT AF, gamma GT bili's }\end{array}$ & O & Handover plan :labresults need & $I_{0}$ & communicatie with doctor \\
\hline & & & goal is 0-balance) & ㅁ & $\begin{array}{l}\text { Neg. Balance because of gastric tube } \\
\text { oroduction }\end{array}$ & $\square$ & Contact doctor, uptain a plan & ( & & & total en direct, amylase & $\omega^{\Delta}$ & |interventions & D & \\
\hline & & & & $\square$ & $k 200 \mathrm{ml}$ in $12 \mathrm{~h}$ & $\square$ & remove gastric tube + start diet & $\square$ & & & amylase in drain ( PACU) & $\square$ & drain has already been removed & $\square$ & Stop control amylase \\
\hline$\square$ & 마 & ㅁ & gastric tube production & 口 & vomiting when Gastrictube is still in situ langs & mala & Repesition gastric tube & $\square$ & $\square$ & & Iumen CVC & $\square$ & Not used lumina CVC & $\square$ & $\begin{array}{l}\text { Heparinisation of unused lumina cVC } \\
\text { according to protocol }\end{array}$ \\
\hline$\square$ & $\square$ & $\square$ & Vomiting & $\square$ & $>300 \mathrm{ml}$ & $\square$ & reposition gastric tube & $\square$ & 口 & $\square$ & 4x daily glucose daycurve & $\square$ & $3.6<$ <glucose $>10$ & 口 & Glucose protocol \\
\hline$\square$ & $\square$ & $\square$ & fluidbalance & $\square$ & $\begin{array}{l}\text { Neg. Balance because of gastric } \\
\text { tube production }\end{array}$ & $\square$ & $\begin{array}{l}\text { uptain a Fluid intake plan together with } \\
\text { doctor for day and night }\end{array}$ & & & & Glucose day curve after initiation of & & & & \\
\hline إ & ( & 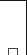 & Drainproduction & $\square$ & \begin{tabular}{|l|}
$\begin{array}{l}\text { No leakage of gal or amylase } \\
(<500 \mathrm{~L} / \mathrm{L}) \text { production }<200 \mathrm{ml} / \text { day }\end{array}$ \\
\end{tabular} & $\square$ & remove drain after consulting pancreassurgeon & $\square$ & $\square$ & & $\begin{array}{l}\text { TPN: } 3 \mathrm{~h} \text { after start TPN and } 6 \mathrm{~h} \text { after } \\
\text { start TPN (Time see start of TPV) }\end{array}$ & $\square$ & Glucose $<5$ en $>15$ & $\square$ & Contact physician \\
\hline & & & & $\square$ & $\begin{array}{l}\text { change of aspect or production > } \\
200 \mathrm{ml} \text { in } 3 \mathrm{~h}\end{array}$ & $\square$ & call doctor & $\square$ & $\square$ & $\square$ & 24 u/dag Comprinetstockings & $\square$ & $\begin{array}{l}\text { sufficient mobilisation(6-8 hours out of } \\
\text { bed and walking) }\end{array}$ & $\square$ & stop comprinet anti thrombose stockings \\
\hline 口 & $\square$ & ㅁ & Diuresis à 3 uur & 口 & $<1 / 2 \mathrm{ml} / \mathrm{kg} / \mathrm{h}$ during. $3 \mathrm{~h}$ & $\square$ & Contact doctor & & & & consultation: dietician, & & & & \\
\hline \begin{tabular}{|c|c|c|c|}
$\square$ \\
\end{tabular} & $\square$ & $\square$ & TPN & $\square$ & $3.6<$ glucose $>10$ & $\square$ & according glucose protocol & ㅁ & $\square$ & $\square$ & \begin{tabular}{|l} 
painteam, physiothapaist, physician \\
lif glucose is not in control according
\end{tabular} & & & & \\
\hline $\mathrm{D}$ & $E$ & $\mathbf{N}$ & Wellbeing & & riance observed & & Intervention & & & & CP) Medical emergency team & & & & \\
\hline 마 & $\square$ & $\square$ & Painscore $<4$ & 口 & NRS $>4$ & $\square$ & Intervention acc painprotocol & & & & & & & & \\
\hline$\square$ & $\square$ & $\square$ & Orientation(time, place, person) & $\square$ & Patiënt is desoriented & $\square$ & $\begin{array}{l}\text { Start DOS registration and Frail protocol } \\
\text { risk for delirium }\end{array}$ & & & $\square$ & $22.00 \mathrm{~h}$ Nadroparine $5700 \mathrm{EH}$ & $\square$ & check NTX, allergy & $\square$ & contact doctor for alternative \\
\hline$\square$ & $\square$ & $\square$ & $\begin{array}{l}\text { Welbeing according to the } \\
\text { patient }\end{array}$ & $\square$ & acceptable for the patiënt & $\square$ & communicate with the patient & & ppor & rtage & & & & & \\
\hline$\square$ & $\square$ & $\square$ & Abdominal pain & $\square$ & $\begin{array}{l}\text { pain, cramps, tense, ructus, } \\
\text { bowelsounds }\end{array}$ & $\square$ & contact doctor & & $\mathrm{rt}$ of T & & . Hour & & & & \\
\hline \begin{tabular}{|l|l|l|l|l} 
D \\
\end{tabular} & $\mathrm{E}$ & $\mathbf{N}$ & Mobilisation & & riance observed & & Intervention & & & & & & & & \\
\hline & $\square$ & & $\begin{array}{l}2 \times 15-30 \text { min. Swing or transfer } \\
\text { to chair }\end{array}$ & $\square$ & $\begin{array}{l}\text { Swing or transfer to chair not } \\
\text { possiblen }\end{array}$ & $\square$ & $\begin{array}{l}\text { Reason has to be rapported in the patients } \\
\text { medical file and further plan }\end{array}$ & & & & & & & & \\
\hline & 足 & & Breathing exercisies & 口 & not sufficient because of pain & $\square$ & contact painteam & & & & & & & & \\
\hline & & & & a & not sufficient but pain is not the reason & $\square$ & contact doctor & & & & & & & & \\
\hline
\end{tabular}




\section{Appendix 3}

\begin{tabular}{|c|c|c|}
\hline UMC (अ) St Radbou & $\begin{array}{c}\text { Variance CP } \\
\text { POSTOPERATIve (day 0/1-2) } \\
\text { Pancreaticoduodenectomy } \\
\text { Date.......... }\end{array}$ & sticker patiënt \\
\hline variance respiratory status & Action & Medical Plan, time, action \\
\hline $\begin{array}{l}\text { Patient is not extubated }<6 \text { hours because } \\
\text { extubation goals are not achieved. }\end{array}$ & $\square$ contact doctor & $\square$ \\
\hline $\begin{array}{c}\text { Variance respiratory status after } \\
\text { extubation }\end{array}$ & Action & Medical Plan, time, action \\
\hline $\begin{array}{l}\mathrm{SpO}_{2}<96 \% \text { (in some patients a lower } \mathrm{SpO} 2 \\
\text { is accepted, this should be part of the written } \\
\text { treatment plan) }\end{array}$ & $\begin{array}{l}\square \text { discuss possible reasons with the patient } \\
\square \text { exclude pain and stress } \\
\square \text { control oxygen supply/device } \\
\square \mathrm{O}_{2} \text { use maxl } 5 \text { ltr } \\
\square \text { control leakage } \\
\text { anasthetics? } \\
\square \text { stimulate efficient coughing (small pillow) } \\
\text { If the result is not enough: } \\
\square \text { check } \mathrm{SpO}_{2} \text { at arrival in the hospital } \\
\square \text { contact doctor } \\
\square \text { start non-rebreathing masker or aquapack } 100 \% \\
\text { after contact with doctor }\end{array}$ & $\begin{array}{l}\text { reason: } \\
\square \\
\square \\
\square \\
\square \\
\square \\
\\
\mathrm{SpO}_{2} \text { at arrival in the hospital }>\ldots \ldots \ldots \ldots \ldots \ldots \ldots . . . . . . . . . . . \\
\square \text { non-rebreathing mask/aquapack } 100 \% \\
\square \text { re- intubation } \\
\text { lower saturation can be accepted }\end{array}$ \\
\hline breathing frequency $>30 /$ minute & $\begin{array}{l}\square \mathrm{SpO}_{2}<96 \% \text { : see variancebij } \mathrm{SpO}_{2}<96 \% \\
\square \mathrm{SpO}_{2} \geq 96 \% \text { : } \\
\text { odiscuss possible reasons with the patient } \\
\text { o exclude pain and stress } \\
\text { o unknown? contact doctor }\end{array}$ & $\begin{array}{l}\square \\
\square \\
\circ \\
\circ \\
\circ \\
\circ\end{array}$ \\
\hline breathing frequency $<10 /$ minute & $\begin{array}{l}\square \text { observe and stimulate the patient } \\
\square \text { reason? Medication? } \\
\square \mathrm{SpO}_{2}<96 \% \text { : see variance } \mathrm{SpO}_{2}<96 \% \\
\square \text { contact doctor if apnoe and/or breathing } \\
\text { frequency }<6 \text { / minute }\end{array}$ & $\begin{array}{l}\square \\
\square \\
\square \\
\square\end{array}$ \\
\hline Variance hemodynamic stability & Action & Medical Plan, time, action \\
\hline $\begin{array}{l}\text { all combinations of hemodynamic changes } \\
\text { including sinusrhythm }>90 / \text { minute) }\end{array}$ & $\begin{array}{l}\square \text { control situation physiology on arrival in the } \\
\text { hospital, contact doctor }\end{array}$ & $\square$ \\
\hline New rhythm and/ of disrhythmia & $\begin{array}{l}\square \text { uptain ECG } \\
\square \text { contact doctor }\end{array}$ & Rhyth analysis: \\
\hline $\mathrm{ABP} M A P<70 \mathrm{~mm} \mathrm{Hg}$ & $\square$ contact doctor & $\square$ \\
\hline $\begin{array}{l}\text { ABP MAP }>100 \mathrm{~mm} \mathrm{Hg} \text { or systolic } \\
\text { bloodpressure }>150 \mathrm{~mm} \mathrm{Hg}\end{array}$ & $\square$ contact doctor & $\square$ \\
\hline $\begin{array}{l}\text { ABP MAP } 70-100 \mathrm{~mm} \mathrm{Hg}: \text { if PiCCO } \\
-\mathrm{Cl}>3,0 \mathrm{l} / \mathrm{min} / \mathrm{m} 2 \\
- \text { ITBVi }<850 \mathrm{ml} / \mathrm{m} 2 \\
- \text { EVLWi }<10 \text { of }>10 \mathrm{ml} / \mathrm{kg}\end{array}$ & $\begin{array}{l}\square \text { If results are not sufficient after } 2 \times 250 \mathrm{ml} \text { : } \\
\text { contact doctor }\end{array}$ & 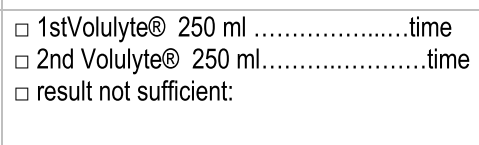 \\
\hline $\begin{array}{l}\text { ABP MAP } 70-100 \mathrm{~mm} \mathrm{Hg:if} \mathrm{PiCCO} \\
-\mathrm{Cl}>3,0 \mathrm{l} / \mathrm{min} / \mathrm{m} 2 \\
- \text { ITBVi }>850 \mathrm{ml} / \mathrm{m} 2 \\
- \text { EVLWi }>10 \mathrm{ml} / \mathrm{kg}\end{array}$ & $\square$ contact doctor & $\square$ \\
\hline
\end{tabular}




\begin{tabular}{|c|c|c|}
\hline $\begin{array}{l}\text { ABP MAP } 70-100 \mathrm{~mm} \mathrm{Hg}: \text { if PiCCO } \\
- \text { CI }<3,0 \mathrm{l} / \mathrm{min} / \mathrm{m} 2 \\
- \text { ITBVi }<850 \mathrm{ml} / \mathrm{m} 2 \\
\text { - EVLWi }<10 \text { of }>10 \mathrm{ml} / \mathrm{kg}\end{array}$ & $\begin{array}{l}\square \text { If results are not sufficient after } 2 \times 250 \mathrm{ml} \text { : } \\
\text { contact doctor }\end{array}$ & 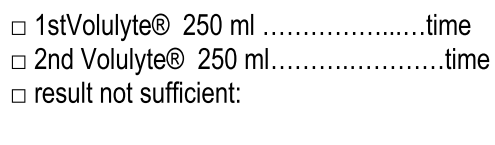 \\
\hline $\begin{array}{l}\text { ABP MAP } 70-100 \mathrm{~mm} \mathrm{Hg}: \text { if PiCCO } \\
-\mathrm{Cl}<3,0 \mathrm{l} / \mathrm{min} / \mathrm{m}^{2} \\
\text { - ITBVi }>850 \mathrm{ml} / \mathrm{m}_{2} \\
\text { - EVLWi }<10 \text { of }>10 \mathrm{ml} / \mathrm{kg}\end{array}$ & $\square$ contact & $\square$ \\
\hline $\mathrm{ScvO}_{2}<70 \%$ & $\square$ contact doctor & $\square$ \\
\hline
\end{tabular}

\begin{tabular}{|c|c|c|}
\hline UMC (艘) St Radbou & $\begin{array}{c}\text { Variance CP POSTOPERATIve(dag 0/1- } \\
\text { 2)pancreaticoduodenectomy } \\
\text { Date...... }\end{array}$ & sticker patiënt \\
\hline Variance Excretion & Action & Medical Plan, time, action \\
\hline Diuresis $<0,5 \mathrm{ml} / \mathrm{kg} / \mathrm{hour}$ & $\begin{array}{l}\square \text { control function of bladder catheter } \\
\square \text { contact doctor }\end{array}$ & $\square$ \\
\hline \multirow[t]{3}{*}{ Abdominal drain leakage } & $\begin{array}{l}\square \text { contact doctor if signs of infection } \\
\square \text { contact doctor if bandage has to be renewed } 2 x \\
\text { per shift because of fluidloss }\end{array}$ & $\begin{array}{l}\square \\
\square\end{array}$ \\
\hline & & Oorzaak: \\
\hline & & $\square$ \\
\hline \multicolumn{2}{|l|}{ Variance Temperature } & Medical Plan, time, action \\
\hline$<35,0^{\circ} \mathrm{C}$ & $\begin{array}{l}\square \\
\square \text { start Bair Hugger } 囚 / \text { heating system } \\
\square \text { breathing air has to be warm if the patient is still } \\
\text { on the ventilator }\end{array}$ & $\begin{array}{l}\square \\
\square \\
\square\end{array}$ \\
\hline$<36,0^{\circ} \mathrm{C}$ & $\begin{array}{l}\square \\
\text { Bair Hugger } 囚 / \text { heating system }\end{array} \square$ start & $\begin{array}{l}\square \\
\square\end{array}$ \\
\hline$>38,0^{\circ} \mathrm{C}$ & $\square$ contact doctor & $\begin{array}{l}\square \text { postoperative inflammatory response of infection } \\
\text { related }\end{array}$ \\
\hline \multicolumn{2}{|l|}{ Variance Pain en Sedation } & Medical Plan, time, action \\
\hline sedated patient & $\begin{array}{l}\square \text { continue sedation if temperature }<36,0^{\circ} \mathrm{C} \\
\square \text { reduce sedation depending on blood results or } \\
\text { stop sedation if temp }>36,0^{\circ} \mathrm{C} \text { and the patient is } \\
\text { hemodynamic and respiratory stable and no } \\
\text { anesthesia (TOF) }\end{array}$ & $\begin{array}{l}\square \text { Start of Sedation reduction ...................hour } \\
\text { Sedatie stop ....................hour }\end{array}$ \\
\hline $\begin{array}{l}\text { NRS }>4 \text { because of wound pain and the } \\
\text { patient is on pain medication }\end{array}$ & $\begin{array}{l}\square \text { control epidural block } \\
60 \text { minuten after start of extra pain medication } \\
\text { (in contact with doctor): } \\
\square \text { New measure of NRS / CPOT } \\
\square \text { communicate with doctor for extra pain } \\
\text { medication } \\
\square \text { contact doctor about the need of diagnostics and } \\
\text { consultation }\end{array}$ & $\begin{array}{l}\square \\
\square \\
\square \\
\square \\
\square\end{array}$ \\
\hline Variance general & Action & Medical Plan, time, action \\
\hline patient lies in a position of $45^{\circ}$ & $\begin{array}{l}\square \text { control } \\
\square \text { if not than put in right position } 45 \text { degrees }\end{array}$ & $\begin{array}{l}\square \\
\square\end{array}$ \\
\hline subcutaneous emphysema & $\square$ contact doctor & $\square$ \\
\hline Patiënt has nausea & $\begin{array}{l}\square \text { Ondansetron } 4 \mathrm{mg} \text { i.v. } \\
\square \text { insufficient result contact doctor }\end{array}$ & $\begin{array}{l}\square \\
\square\end{array}$ \\
\hline Patiënt has fear and stress & $\begin{array}{l}\square \text { communicate fear and sress with the patient } \\
\square \text { insufficient result contact doctor }\end{array}$ & $\begin{array}{l}\square \\
\square\end{array}$ \\
\hline
\end{tabular}




\begin{tabular}{|c|c|c|}
\hline Variance Labresults & Action & Medical Plan, time, action \\
\hline Glucose $<6,0 \mathrm{mmol} / \mathrm{l}$ & $\square$ glucose protocol & $\square$ \\
\hline Glucose $>8,0 \mathrm{mmol} / \mathrm{l}$ & $\begin{array}{l}\text { 1st result at PACU//CU entrance glucose }>8,0 \\
\mathrm{mmol} / \mathrm{l} \text { : } \\
\square \text { control after } 1 \text { hour } \\
\text { If second result or every other result after the first is } \\
>8,0 \mathrm{mmol} / \mathrm{l} \text { : } \\
\square \text { glucose protocol PACU/ICU }\end{array}$ & $\begin{array}{l}\square \\
\square\end{array}$ \\
\hline
\end{tabular}

Open Access This article is distributed under the terms of the Creative Commons Attribution 4.0 International License (http:// creativecommons.org/licenses/by/4.0/), which permits unrestricted use, distribution, and reproduction in any medium, provided you give appropriate credit to the original author(s) and the source, provide a link to the Creative Commons license, and indicate if changes were made.

\section{References}

1. Hsu CC, Wolfgang CL, Laheru DA, Pawlik TM, Swartz MJ, Winter JM, et al. Early mortality risk score: identification of poor outcomes following upfront surgery for resectable pancreatic cancer. Journal of Gastrointestinal Surgery. 2012;16(4):753-61.

2. Hata T, Motoi F, Ishida M, Naitoh T, Katayose Y, Egawa S, et al. Effect of hospital volume on surgical outcomes after pancreaticoduodenectomy: a systematic review and meta-analysis. Annals of Surgery. 2016;263(4):664-72.

3. Hyder O, Dodson RM, Nathan H, et al. Influence of patient, physician, and hospital factors on 30-day readmission following pancreatoduodenectomy in the united states. JAMA Surgery. 2013;148(12):1095-102.

4. Cameron JL, He J. Two thousand consecutive pancreaticoduodenectomies. Journal of the American College of Surgeons. 2015;220(4):530-6.

5. Polle SW, Wind J, Fuhring JW, Hofland J, Gouma DJ, Bemelman WA. Implementation of a fast-track perioperative care program: what are the difficulties? Digestive Surgery. 2007;24(6):441-9.

6. Kahokehr A, Sammour T, Zargar-Shoshtari K, Thompson L, Hill AG. Implementation of ERAS and how to overcome the barriers. International Journal of Surgery. 2009;7(1):16-9.

7. De Bleser L, Depreitere R, Waele KD, Vanhaecht K, Vlayen J, Sermeus W. Defining pathways. Journal of Nursing Management. 2006;14(7):553-63.

8. Pucher P, Aggarwal R, Singh P, Darzi A. Enhancing surgical performance outcomes through process-driven care: a systematic review. World Journal of Surgery. 2014;38(6):1362-73.

9. Gatt M, Anderson ADG, Reddy BS, Hayward-Sampson P, Tring IC, MacFie J. Randomized clinical trial of multimodal optimization of surgical care in patients undergoing major colonic resection. British Journal of Surgery. 2005;92(11):1354-62.

10. Ronellenfitsch U, Schwarzbach M, Kring A, Kienle P, Post S, Hasenberg T. The effect of clinical pathways for bariatric surgery on perioperative quality of care. OBES SURG. 2012;22(5):732-9.

11. Schwarzbach M, Hasenberg T, Linke M, Kienle P, Post S, Ronellenfitsch U. Perioperative quality of care is modulated by process management with clinical pathways for fast-track surgery of the colon. International Journal of Colorectal Disease. 2011;26(12):1567-75.
12. Trussell J, Gerkin R, Coates B, Brandenberger J, Tibi P, Keuth J, et al. Impact of a patient care pathway protocol on surgical site infection rates in cardiothoracic surgery patients. The American Journal of Surgery. 2008;196(6):883-9.

13. Dy SM, Garg P, Nyberg D, Dawson PB, Pronovost PJ, Morlock L, et al. Critical pathway effectiveness: assessing the impact of patient, hospital care, and pathway characteristics using qualitative comparative analysis. Health Services research. 2005;40(2):499-516.

14. Ford SR, Pearse RM. Do integrated care pathways have a place in critical care? Current opinion in critical care. 2012;18(6):683-7 10. 1097/MCC.0b013e328357a2f5.

15. Nussbaum DP, Penne K, Stinnett SS, Speicher PJ, Cocieru A, Blazer Iii DG, et al. A standardized care plan is associated with shorter hospital length of stay in patients undergoing pancreaticoduodenectomy. Journal of Surgical Research. 2015;193(1):237-45.

16. Coolsen MME, van Dam RM, Chigharoe A, Olde Damink SWM, Dejong CHC. Improving outcome after pancreaticoduodenectomy: experiences with implementing an enhanced recovery after surgery (ERAS) program. Digestive Surgery. 2014;31(3):177-84.

17. Sutcliffe RP, Hamoui M, Isaac J, Marudanayagam R, Mirza DF, Muiesan $\mathrm{P}$, et al. Implementation of an enhanced recovery pathway after pancreaticoduodenectomy in patients with low drain fluid amylase. World Journal of Surgery. 2015;39(8):2023-30.

18. Walters DM, McGarey P, LaPar DJ, Strong A, Good E, Adams RB, et al. A 6-day clinical pathway after a pancreaticoduodenectomy is feasible, safe and efficient. HPB. 2013;15(9):668-73.

19. Kennedy EP, Rosato EL, Sauter PK, Rosenberg LM, Doria C, Marino IR, et al. Initiation of a critical pathway for pancreaticoduodenectomy at an academic institution - the first step in multidisciplinary team building. Journal of the American College of Surgeons. 2007;204(5):917-23.

20. Ackland GLA, Edwards MB Defining higher-risk surgery. Current Opinion in Critical Care. 2010;16(4):339-46.

21. Pearse RM, Ackland GL. Perioperative fluid therapy. BMJ. 2012;344.

22. Gerritsen A, Besselink M, Cieslak K, Vriens M, Steenhagen E, Hillegersberg R, et al. Efficacy and complications of nasojejunal, jejunostomy and parenteral feeding after pancreatico?duodenectomy. Journal of Gastrointestinal Surgery. 2012;16(6):1144-51.

23. Gerritsen A, Besselink MGH, Gouma DJ, Steenhagen E, Borel Rinkes IHM, Molenaar IQ. Systematic review of five feeding routes after pancreatoduodenectomy. British Journal of Surgery. 2013;100(5):589-98.

24. Lassen K, Coolsen MME, Slim K, Carli F, de Aguilar-Nascimento JE, Schäfer M, et al. Guidelines for perioperative care for pancreaticoduodenectomy: Enhanced Recovery After Surgery (ERAS $®)$ Society recommendations. Clinical Nutrition. 2012;31(6):817-30.

25. Munitiz V, Martinez-de-Haro LF, Ortiz A, Ruiz-de-Angulo D, Pastor P, Parrilla P. Effectiveness of a written clinical pathway for 
enhanced recovery after transthoracic (Ivor Lewis) oesophagectomy. British Journal of Surgery. 2010;97(5):714-8.

26. Abu Hilal M, Di Fabio F, Badran A, Alsaati H, Clarke H, Fecher I, et al. Implementation of enhanced recovery programme after pancreatoduodenectomy: a single-centre UK pilot study. Pancreatology. 2013;13(1):58-62.

27. Hilal MA, Layfield DM, Di Fabio F, Arregui-Fresneda I, Panagiotopoulou IG, Armstrong TH, et al. Postoperative chyle leak after major pancreatic resections in patients who receive enteral feed: risk factors and management options. World Journal of Surgery. 2013;37(12):2918-26.

28. Bosch M, van der Weijden T, Wensing M, Grol R. Tailoring quality improvement interventions to identified barriers: a multiple case analysis. J Eval Clin Pract. 2007;13(2):161-8.

29. Evans-Lacko S, Jarrett M, McCrone P, Thornicroft G. Facilitators and barriers to implementing clinical care pathways. Health Services research. 2010;10:182-7.

30. Lemmens L, Van Zelm R, Vanhaecht K, Kerkkamp H. Systematic review: indicators to evaluate effectiveness of clinical pathways for gastrointestinal surgery. Journal of Evaluation in Clinical Practice. 2008;14(5):880-7.

31. Cathy L, Decramer M, Sermeus W, Panella M, Deneckere S, Vanhaecht K. Eight-step method to build the clinical content of an evidence-based care pathway: the case for COPD exacerbation. Trials. 2012;13.

32. Grol R, Grimshaw J. From best evidence to best practice: effective implementation of change in patients' care. The Lancet. 2003;362(9391):1225-30.

33. van der Kolk M., van den Boogaard M., ter Brugge-Speelman C., Hol J., Noyez L., van Laarhoven C., et al. Development and implementation of a clinical pathway for cardiac surgery in the intensive care unit: effects on protocol adherence.(submitted)

34. Hollis RH, Graham LA, Lazenby JP, Brown DM, Taylor BB, Heslin MJ, et al. A role for the early warning score in early identification of critical postoperative complications. Annals of Surgery. 2016;263(5):918-23.

35. Dvir D, Cohen J, Singer P. Computerized energy balance and complications in critically ill patients: an observational study. Clinical Nutrition. 2006;25(1):37-44.

36. Lu JW, Liu C, Du ZQ, Liu XM, Lv Y, Zhang XF. Early enteral nutrition vs parenteral nutrition following pancreaticoduodenectomy: experience from a single center. World J Gastroenterol. 2016;22(14):3821-8.

37. Casaer MP, Mesotten D, Hermans G, Wouters PJ, Schetz M, Meyfroidt G, et al. Early versus late parenteral nutrition in critically ill adults. New England Journal of Medicine. 2011(0)

38. Afaneh C, Gerszberg D, Slattery E, Seres DS, Chabot JA, Kluger MD. Pancreatic cancer surgery and nutrition management: a review of the current literature. Hepatobiliary Surgery and Nutrition. 2015;4(1):59-71.

39. Hiroshi Katayama, Yukinori Kurokawa, Nakamura K, Hiroyuki Ito, Yukihide Kanemitsu, Norikazu Masuda, et al. Extended ClavienDindo classification of surgical complications: Japan Clinical Oncology Group postoperative complications criteria. Surg Today. 2016(46):18.

40. Braga M, Pecorelli N, Ariotti R, Capretti G, Greco M, Balzano G, et al. Enhanced recovery after surgery pathway in patients undergoing pancreaticoduodenectomy. World Journal of Surgery. 2014;38(11):2960-6.

41. B.M. van der Kolk, M. van den Boogaard, G. Peeters, J.J. Bonenkamp, C.J.H.M. van Laarhoven, J.G. van der Hoeven, et al. Effects related to ScvO2-guided preoperative optimisation in open transhiatal oesophagectomy patients: an observational evaluation study. Neth J Crit Care May 2016;24(3): 19-15. Netherlands Journal of Critical Care. 2016;24(3): 15-9. 